\title{
Evidence of vitamin E deficiency in patients with malabsorption or alcoholism and the effects of therapy
}

\author{
M. S. LOSOWSKY AND P. J. LEONARD
}

From Department of Medicine, The General Infirmary, Leeds

\begin{abstract}
EDITORIAL COMMENT The need for further consideration of vitamin E deficiency in malabsorption and malnutrition states is demonstrated by this study.
\end{abstract}

Diseases due to deficiency of vitamin E are recognized in a number of animal species (Mason and Emmel, 1945; Gatz and Houchin, 1951; Blaxter, Watts, and Wood, 1952; Dinning and Day, 1957) but no well-defined clinical syndrome has been delineated in man. In animals, dietary deprivation of vitamin $E$ results in low plasma levels of the vitamin, abnormal haemolysis of erythrocytes on exposure to hydrogen peroxide, creatinuria, and the deposition of ceroid pigment in various tissues. Similar findings have been reported in man in conditions which may be associated with intestinal malabsorption (Pappenheimer and Victor, 1946; Nitowsky, Cornblath, and Gordon, 1956; Braunstein, 1961; Binder, Herting, Hurst, Finch, and Spiro, 1965; Leonard, Losowsky, and Pulvertaft, 1966). Restriction of the dietary intake of vitamin $\mathrm{E}$ in healthy subjects has led to changes similar to those in deficient animals (Horwitt, Harvey, Duncan, and Wilson, 1956; Horwitt, 1962), and low plasma vitamin E levels have also been reported in malnourished subjects (Harris, Hickman, Jensen, and Spies, 1946).

The present study describes the effect of administering $\alpha$-tocopherol to patients with deficiency of vitamin E secondary to a variety of clinical conditions which would be expected to be associated with malabsorption or malnutrition.

\section{PATIENTS STUDIED}

Eleven patients (Table I) were selected for study on the basis of subnormal plasma vitamin $E$ levels, the lower limit of normal being taken as $0.5 \mathrm{mg} . \%$ (Goldbloom, 1960; Leitner, Moore, and Sharman, 1960). All subjects had been on a normal diet except no. 7 who had been on a moderately low fat diet for the preceding six months, and the three patients with alcoholism who had been taking a very poor diet for a considerable period of time.

All studies were carried out on a metabolic ward. For the entire period of study, subjects were ambulant and maintained on a diet as close as possible to their home diet, but alcohol was omitted in the alcoholic patients (one of whom, patient no. 11, had been in hospital continuously without alcohol for seven weeks preceding investigation). There was an initial period of equilibration of three to five days before starting collection of samples for the control period.

\section{METHODS}

FAECAL FAT EXCRETION Faecal collections were for periods of seven days, using carmine markers. Faecal fat was estimated by the method of van de Kamer, Huinink, and Weyers (1949).

VITAMIN E IN PLASMA Venous blood was taken into dried heparinized tubes. Plasma was separated immediately and stored at $-15^{\circ} \mathrm{C}$. Estimations were performed within one week. Results were unaffected by storage for up to two months. Susceptibility of fresh erythrocytes to haemolysis by hydrogen peroxide was determined as described by Rose and György (1952). In all except one subject glucose was added to the incubation medium as described by Horwitt (1962). Plasma vitamin E levels were estimated as described by Martinek (1964).

URINARY CREATINE AND CREATININE Twenty-four hour urine specimens were collected and the creatine and creatinine contents measured as described by Varley (1962). To overcome the inherent errors of this technique, all analyses were performed in triplicate and then repeated.

All other estimations were performed in duplicate.

RESPONSE TO VITAMIN E Vitamin E was administered as $\alpha$-tocopherol (Ephynal, Roche) $100 \mathrm{mg}$. intramuscularly and $100 \mathrm{mg}$. twice daily orally for seven days and $100 \mathrm{mg}$. twice daily orally thereafter until the end of the study.

\section{RESULTS}

CLINICAL FINDINGS The age, sex, diagnosis, and pre-treatment haemoglobin levels are shown in Table I. 
The reticulocyte count was below the upper limit of normal $(2 \%)$ in all subjects.

Faecal fat output was normal (less than 6 g. per day) in the three subjects with alcoholism, and was abnormal in all other subjects (Table I).

PLASMA VITAMIN E LEVELS AND PEROXIDE HAEMOLYSIS TESTS The mean peroxide haemolysis test was above the upper limit of normal $(4 \%)$ in all except two subjects (Table I).

The plasma vitamin $\mathrm{E}$ level and haemolysis test were performed simultaneously on 18 occasions in the 11 patients before treatment, and these results are plotted in Figure 1. There was a reasonably close inverse correlation between these two parameters of vitamin $E$ deficiency $(P<0.02)$, which also held after treatment. These findings are in keeping with other investigations of the relationship between these tests (Horwitt et al., 1956; Leonard and Losowsky, 1967).

During the control period the haemolysis test, plasma vitamin $\mathrm{E}$ level, and urinary creatine and creatinine showed no consistent change in any subject.

URINARY CREATINE EXCRETION In normal men, creatine is usually not detectable in the urine although up to $40 \mathrm{mg}$. may be excreted on an occasional day. In normal women values in excess of this may be found during menstruation which did not occur during the period of study in any of our three female patients. All subjects except patient no. 9 showed values above $40 \mathrm{mg}$. per day on more than one occasion, even though the mean value for the six days before treatment was slightly less than this figure in two subjects (Table I). Urinary creatine, whether expressed as milligrams per day or as a

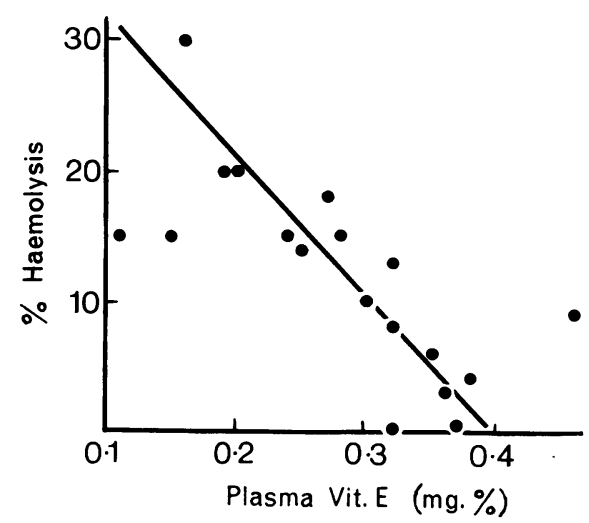

FIG. 1. Relationship between plasma vitamin $E$ level and haemolysis test before treatment. An inverse correlation is shown.

ratio to creatinine, was found to vary considerably in the same patient from day to day. Some of this variation may have been due to inaccuracy of measurement of creatine, but it is felt that this is not a major source of error since the estimations on each sample were performed six times in two separate batches and results agreed well. The creatine excretion before treatment correlated significantly with the haemolysis test $(P<0.001)$; the correlation with the plasma vitamin $E$ level, while suggestive, did not reach statistical significance.

\section{EFFECTS OF TREATMENT}

PLASMA VITAMIN E LEVELS AND PEROXIDE HAEMOLYSIS TESTS Plasma vitamin E levels almost always rose into the normal range (>0.5 $\mathrm{mg} . \%$ ) within a few days of starting supplementation. The levels reached

TABLE I

CLINICAL SUMMARY

\begin{tabular}{|c|c|c|c|c|c|c|c|c|}
\hline \multirow{2}{*}{$\begin{array}{l}\text { Patient } \\
\text { No. }\end{array}$} & \multirow[t]{2}{*}{ Age } & \multirow[t]{2}{*}{$\operatorname{Sex}$} & \multirow{2}{*}{$\begin{array}{l}H b \\
(\%)\end{array}$} & \multirow[t]{2}{*}{ Diagnosis } & \multicolumn{4}{|c|}{ Mean Pre-treatment Value } \\
\hline & & & & & $\begin{array}{l}\text { Faecal } \\
\text { Fat } \\
\text { (g./day) }\end{array}$ & $\begin{array}{l}\text { Plasma } \\
\text { Vitamin } \\
\text { E } \\
\text { (mg. } \%)\end{array}$ & $\begin{array}{l}\text { Peroxide } \\
\text { Haemo- } \\
\text { lysis } \\
(\%)\end{array}$ & $\begin{array}{l}\text { Mean } \\
\text { Urinary } \\
\text { Creatine } \\
\text { (mg./24 hr.) }\end{array}$ \\
\hline $\begin{array}{r}1 \\
2 \\
3 \\
4 \\
5 \\
6 \\
7 \\
8 \\
9 \\
10 \\
11\end{array}$ & $\begin{array}{l}73 \\
68 \\
52 \\
73 \\
46 \\
71 \\
64 \\
41 \\
46 \\
56 \\
62\end{array}$ & $\begin{array}{l}\mathbf{M} \\
\mathbf{M} \\
\mathbf{M} \\
\mathbf{M} \\
\mathbf{M} \\
\mathbf{F} \\
\mathbf{M} \\
\mathbf{F} \\
\mathbf{M} \\
\mathbf{M} \\
\mathbf{F}\end{array}$ & $\begin{array}{r}88 \\
88 \\
96 \\
57 \\
90 \\
58 \\
106 \\
86 \\
106 \\
92 \\
83\end{array}$ & $\begin{array}{l}\text { Partial gastrectomy, diabetes } \\
\text { Partial gastrectomy } \\
\text { Partial gastrectomy, cirrhosis } \\
\text { Total gastrectomy in } 1948 \\
\text { Gluten-induced enteropathy } \\
\text { Gluten-induced enteropathy, pulmonary tuberculosis } \\
\text { Small intestinal resection following volvulus } \\
\text { Primary biliary cirrhosis } \\
\text { Alcoholism, cirrhosis, diabetes } \\
\text { Alcoholism, no cirrhosis } \\
\text { Alcoholism, cirrhosis }\end{array}$ & $\begin{array}{l}24 \\
11 \\
25 \cdot 2 \\
9 \\
24 \\
33 \\
12 \\
38 \\
3 \cdot 7 \\
2 \cdot 4 \\
2\end{array}$ & $\begin{array}{l}0.22 \\
0.28 \\
0.37 \\
0.31 \\
0.17 \\
0.22 \\
0.17 \\
0.42 \\
0.32 \\
0.37 \\
0.29\end{array}$ & $\begin{array}{c}11 \\
18 \\
0 \\
5 \\
62^{1} \\
24 \\
18 \\
10 \\
10 \\
4 \\
15\end{array}$ & $\begin{array}{r}94 \\
188 \\
39 \\
48 \\
75 \\
191 \\
203 \\
283 \\
3 \\
36 \\
128\end{array}$ \\
\hline
\end{tabular}

'Incubated without glucose, which may cause high values. 
after one week of treatment fell between 0.55 and $1 \cdot 12 \mathrm{mg} . \%$ in all subjects.

The haemolysis test became negative in all subjects within the first four days of supplementation except in patient no. 1 in whom 10 days were required.

URINARY CREATINE EXCRETION Vitamin E therapy was followed by a fall in urinary creatine levels, but there was considerable variation in the time taken for maximal improvement. The time taken for urinary creatine to fall to very low levels did not appear to depend on the initial values. Figures 2 and 3 show results in two patients (nos. 7 and 4) in one of whom the response was very rapid while in the other the response was slower, and very low values were not obtained until after many weeks of treatment.

Creatinine output showed no consistent change after therapy in any of the patients during these studies.

Figure 4 shows the urinary creatine-creatinine ratios in all 11 patients in the six days immediately after starting treatment as compared with the six control days, and all except two showed a fall. It should be remembered, however, that looking at the results in this way will mask the effect of therapy in those patients in whom the response does not occur early. This is illustrated in the final column of Fig. 4 which shows that in all the four subjects (nos. 1, 6, 8 , and 11 ) in whom the mean values remained considerably elevated during the first six days after starting treatment, there was a fall during the next four days. Even after this time, however, the values in these subjects were still abnormal.

\section{DISCUSSION}

These patients were selected for study on the basis of a low plasma vitamin $E$ level. In eight of the 11 there was a well-defined cause for malabsorption and the faecal fat excretion was abnormal. It seems likely that, in these subjects, the low plasma vitamin $\mathbf{E}$ level might be attributable to malabsorption since this is a fat-soluble vitamin. In the remaining three subjects in whom there was a history of a poor dietary intake, the deficiency may well have been of dietary origin.

Abnormalities of the plasma vitamin E level, the haemolysis test, and the urinary excretion of creatine occurred together in these subjects, and thus it would appear that these are all interrelated aspects of vitamin $\mathrm{E}$ deficiency, as reported in animals (Melville and Hummel, 1951; Blaxter et al., 1952; Dinning and Day, 1957). Although there is usually a good correlation between the plasma vitamin $\mathbf{E}$ level and the peroxide haemolysis test, this does not hold in every instance (Leonard and Losowsky, 1967).

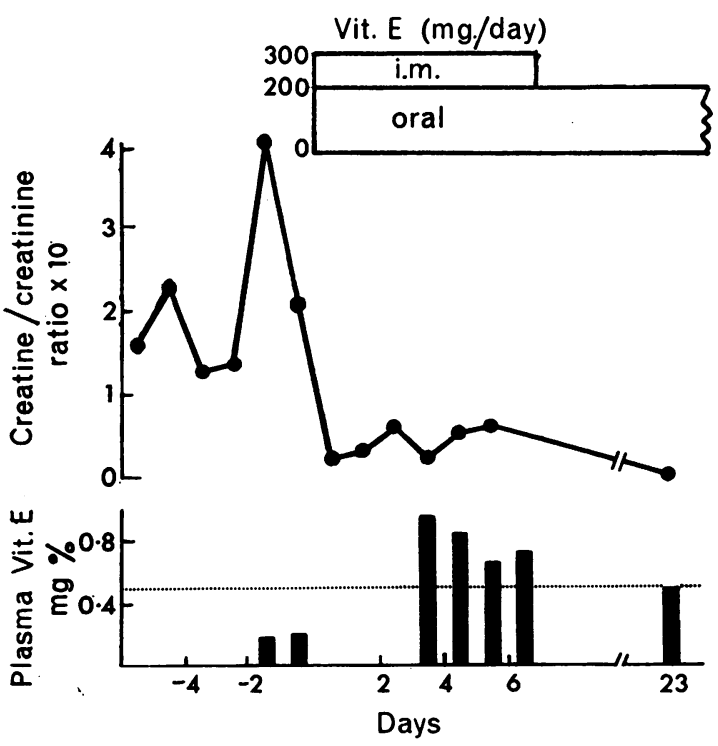

FIG. 2

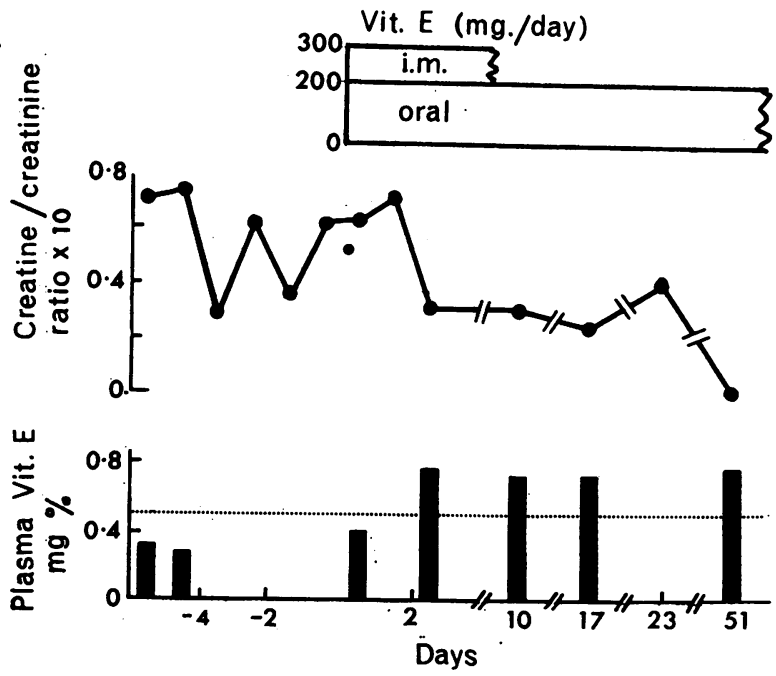

FIG. 3

FIG. 2. Effect of therapy in subject no. 7. Urinary 24-hour creatine-creatinine ratio was initially very high and fell rapidly after therapy.

FIG. 3. Effect of therapy in subject no. 4. Urinary 24-hour creatine-creatinine ratio showed a slow response to therapy. 


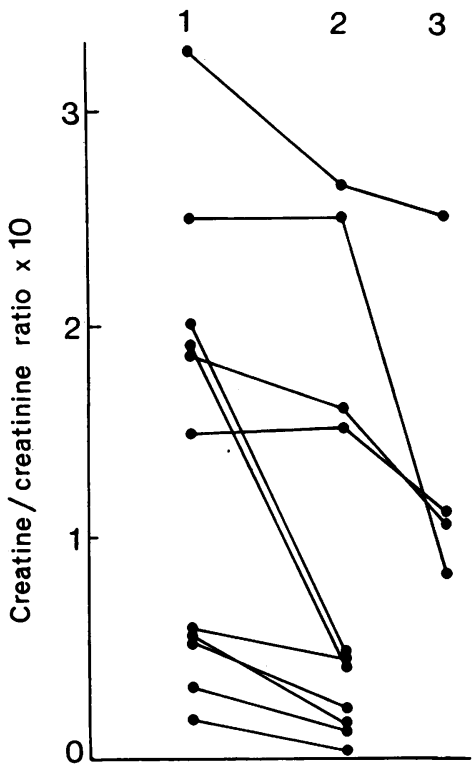

FIG. 4. Urinary 24-hour creatine-creatinine ratios before and after vitamin $E$ therapy: column 1, mean value for six days before treatment; column 2, mean value for days 1-6 after starting treatment; column 3, mean value for days 7-10 after treatment. All patients showed a diminution with treatment.

This study shows that in patients with evidence of vitamin $\mathrm{E}$ deficiency, raising the plasma vitamin $\mathrm{E}$ level by the administration of $\alpha$-tocopherol is followed by a return of the haemolysis test to normal and a fall in urinary creatine excretion. Considerable variation was noted in the rapidity of the rise in plasma vitamin $E$ level and fall in urinary creatine excretion after supplementation, which might be expected as the degree and duration of vitamin $\mathrm{E}$ depletion would probably differ in different subjects. In one subject the urinary excretion of creatine was negligible throughout the study, and it is interesting to note that this subject had a large and rapid rise in the plasma level following administration of the vitamin, suggesting an initiaily mild degree of depletion. In four subjects considerable creatine excretion persisted during the first six days of therapy. This could be due either to additional causes of creatinuria or to inadequacy of the period of supplementation, as suggested by the response which occurred in each subject during a further four days of therapy. Other causes of creatinuria might be suspected in two of these subjects (nos. 6 and 11), one of whom was found to have active pulmonary tuberculosis while the other had cirrhosis of the liver (Thompson, 1930; Nitzescu and Gontzea, 1937).
The creatinuria of vitamin E deficiency presumably reflects a lack of an action of the vitamin on striated muscle metabolism, resulting either in impaired retention of muscle creatine, or diminished uptake of creatine from the blood (Fitch, Coker, and Dinning, 1960; Gerber, Gerber, Koszalka, and Emmel, 1962). Whichever mechanism is responsible, the rapid reversal of the creatinuria makes it possible that muscle bulk might be regained following vitamin $\mathrm{E}$ therapy, although this might only be apparent after prolonged treatment.

Anaemia associated with vitamin E deficiency has been described in animals (Dinning and Day, 1957) and in man (Marvin and Audu, 1964), but in our subjects there was anaemia in only two, one of whom also had active pulmonary tuberculosis. A normal haemoglobin concentration does not, however, rule out the possibility of a compensated haemolytic state, and in another study (Losowsky and Leonard, 1967) improvement in red cell survival was associated with supplementation of the vitamin in deficient subjects.

Our results confirm that in human disease deficiency of vitamin $\mathrm{E}$ occurs and is associated with changes similar to those found following dietary deprivation of vitamin $\mathrm{E}$ in animals, and that supplementation can reverse these findings. This raises the questions of whether deficiency of vitamin E should be looked for more often in malnutrition and malabsorption and whether replacement therapy should be considered.

\section{SUMMARY}

Eleven subjects with evidence of vitamin E deficiency secondary to poor diet or malabsorption have been studied.

Low plasma vitamin E levels, abnormal haemolysis of red cells by hydrogen peroxide, and creatinuria can all be reversed by administration of $\alpha$-tocopherol. The desirability of therapy with vitamin $E$ in such subjects should be considered.

We would like to thank the nursing and laboratory staff of our metabolic unit, and Roche Products Ltd. for initial supplies of $\alpha$-tocopherol.

\section{REFERENCES}

Binder, H. J., Herting, D. C., Hurst, V., Finch, S. C., and Spiro, H. M. (1965). Tocopherol deficiency in man. New Engl. J. Med., 273, 1289-1297.

Blaxter, K. L., Watts, P. S., and Wood, W. A. (1952). The nutrition of the young Ayrshire calf. 8. Muscular dystrophy in the growing calf. Brit. J. Nutr., 6, 125-144.

Braunstein, H. (1961). Tocopherol deficiency in adults with chronic pancreatitis. Gastroenterology, 40, 224-231.

Dinning, J. S., and Day, P. L. (1957). Vitamin E deficiency in the monkey. I. Muscular dystrophy, hematologic changes, and the excretion of urinary nitrogenous constituents. J. exp. Med., 105, 395-402. 
Fitch, C. D., Coker, R., and Dinning, J. S. (1960). Metabolism of creatine-I-C ${ }^{14}$ by vitamin E-deficient and hyperthyroid rats. Amer. J. Physiol., 198, 1232-1234.

Gatz, A. J., and Houchin, O. B. (1951). Studies on the heart of Vitamin E deficient rabbits. Anat. Rec., 110, 249-260.

Gerber, G. B., Gerber, G., Koszalka, T. R., and Emmel, V. M. (1962). Creatinine metabolism in vitamin $\mathrm{E}$ deficiency in the rat. Amer. J. Physiol., 202, 453-460.

Goldbloom, R. B. (1960). Investigations of tocopherol deficiency in infancy and childhood. Studies of serum tocopherol levels and of erythrocyte survival. Canad. med. Ass. J., 82, 1114-1117.

Harris, P. L., Hickman, K. C. D., Jensen, J. L., and Spies, T. D. (1946). Survey of the blood plasma levels of vitamin A, carotene, ascorbic acid, and tocopherols of persons in an area of endemic malnutrition. Amer. J. publ. Hlth, 36, 155-160.

Horwitt, M. K. (1962). Interrelations between vitamin E and polyunsaturated fatty acids in adult men. Vitam. and Hormon., 20, 541-558.

—, Harvey, C. C., Duncan, G. D., and Wilson, W. C. (1956). Effects of limited tocopherol intake in man with relationships to erythrocyte hemolysis and lipid oxidations. Amer. J. clin. Nutr., 4, 408-419.

Kamer, J. M. van de, Huinink, H. ten B., and Weyers, H. A. (1949). Rapid method for the determination of fat in feces. J. biol. Chem., 177, 347-355.

Leitner, Z. A., Moore, T., and Sharman, I. M. (1960). Vitamin A and vitamin $E$ in human blood. 2. Levels of vitamin $E$ in the blood of British men and women, 1952-7. Brit. J. Nutr., 14, 281-287.
Leonard, P. J., and Losowsky, M. S. (1967). Relationship between plasma vitamins $E$ level and peroxide hemolysis test in human subjects. Amer. J. Clin. Nutr., 20, 795-798.

,-- and Pulvertaft, C. N. (1966). Vitamin E levels after gastric surgery. Gut, 7, 578-580.

Losowsky, M. S., and Leonard, P. J. (1967). In preparation.

Martinek, R. G. (1964). Method for the determination of vitamin E (total tocopherols) in serum. Clin. Chem., 10, 1078-1086.

Marvin, H. N., and Audu, I. S. (1964). A preliminary study of vitamin $\mathrm{E}$ and the anaemia of kwashiorkor. West Afr. med. J., 13, 3-8.

Mason, K. E., and Emmel, A. F. (1945). Vitamin E and muscle pigment in rat. Anat. Rec., 92, 33-59.

Melville, R. S., and Hummel, J. P. (1951). Creatine and glycocyamine metabolism in rabbits in vitamin E deficiency. J. biol. Chem., 191, 383-389.

Nitowsky, M. M., Cornblath, M., and Gordon, H. H. (1956). Studies of tocopherol deficiency in Infants and Children. II. Plasma tocopherol and erythrocyte hemolysis in hydrogen peroxide. Amer. J. Dis. Child., 92, 164-174.

Nitzescu, I. I., and Gontzea, I. (1937). Le Foie et la Créatinurie. C. R. Soc. Biol. (Paris), 125, 77-80.

Pappenheimer, A. M., and Victor, J. (1946). 'Ceroid' pigment in human tissues. Amer. J. Path., 22, 395-413.

Rose, C. S., and György, P. (1952). Specificity of hemolytic reaction in vitamin E deficient erythrocytes. Amer. J. Physiol., 168, 414-420.

Thompson, J. T. (1930). Creatinuria in tuberculosis. I. Creatinuria in tuberculous men. J. Lab. clin. Med., 16, 5-12.

Varley, H. (1962). Practical Clinical Biochemistry, 3rd ed. Heinemann, London. 